\title{
Initial nutritional management during noninvasive ventilation and outcomes: a retrospective cohort study
}

\author{
Nicolas Terzi ${ }^{1,2^{*}}$, Michael Darmon ${ }^{3}$, Jean Reignier ${ }^{4}$, Stéphane Ruckly ${ }^{5,6}$, Maïté Garrouste-Orgeas ${ }^{7}$, \\ Alexandre Lautrette ${ }^{8}$, Elie Azoulay ${ }^{9}$, Bruno Mourvillier ${ }^{6,10}$, Laurent Argaud ${ }^{11}$, Laurent Papazian ${ }^{12}$, Marc Gainnier ${ }^{13}$, \\ Dan Goldgran-Toledano ${ }^{14}$, Samir Jamali ${ }^{15}$, Anne-Sylvie Dumenil ${ }^{16}$, Carole Schwebel ${ }^{2,17}$ and Jean-François Timsit ${ }^{6,10}$ \\ for the OUTCOMEREA study group
}

\begin{abstract}
Background: Patients starting noninvasive ventilation (NIV) to treat acute respiratory failure are often unable to eat and therefore remain in the fasting state or receive nutritional support. Maintaining a good nutritional status has been reported to improve patient outcomes. In the present study, our primary objective was to describe the nutritional management of patients starting first-line NIV, and our secondary objectives were to assess potential associations between nutritional management and outcomes.

Methods: Observational retrospective cohort study of a prospective database fed by 20 French intensive care units. Adult medical patients receiving NIV for more than 2 consecutive days were included and divided into four groups on the basis of nutritional support received during the first 2 days of NIV: no nutrition, enteral nutrition, parenteral nutrition only, and oral nutrition only.
\end{abstract}

Results: Of the 16,594 patients admitted during the study period, 1075 met the inclusion criteria; of these, 622 (57.9\%) received no nutrition, 28 (2.6\%) received enteral nutrition, 74 (6.9\%) received parenteral nutrition only, and 351 (32.7\%) received oral nutrition only. After adjustment for confounders, enteral nutrition (vs. no nutrition) was associated with higher 28-day mortality (adjusted HR, 2.3; 95\% Cl, 1.2-4.4) and invasive mechanical ventilation needs (adjusted HR, 2.1; $95 \% \mathrm{Cl}, 1.1-4.2$ ), as well as with fewer ventilator-free days by day 28 (adjusted relative risk, $0.7 ;$; $95 \% \mathrm{Cl}, 0.5-0.9$ ).

Conclusions: Nearly three-fifths of patients receiving NIV fasted for the first 2 days. Lack of feeding or underfeeding was not associated with mortality. The optimal route of nutrition for these patients needs to be investigated.

Keywords: Nutrition, Noninvasive mechanical ventilation, Intensive care unit, Acute respiratory failure, Pneumonia

\section{Background}

Over the last two decades, noninvasive ventilation (NIV) has become the cornerstone supportive treatment for acute respiratory failure requiring intensive care unit (ICU) admission. NIV decreases the need for endotracheal mechanical ventilation (MV), which is a major source of complications. NIV has been proven to decrease mortality, particularly in patients experiencing

\footnotetext{
* Correspondence: nterzi@chu-grenoble.fr

${ }^{1}$ INSERM, U1042, Université Grenoble-Alpes, HP2, F-38000 Grenoble, France

${ }^{2}$ Service de Réanimation Médicale, Centre Hospitalier Universitaire Grenoble

- Alpes, CS10217 Grenoble, cedex 09, France

Full list of author information is available at the end of the article
}

acute exacerbations of chronic obstructive pulmonary disease (COPD) or acute cardiogenic pulmonary edema $[1,2]$. Both acute respiratory failure and COPD may induce malnutrition, which may adversely affect patient outcomes [3-6]. However, no recommendations about nutritional support to patients receiving NIV are available.

Patients may be unable to remain off NIV for a sufficient time to allow adequate food ingestion or may feel too short of breath to eat. Either enteral nutrition via a nasogastric tube or parenteral nutrition can be used in this situation. Enteral nutrition has been associated with a lower infection rate than parenteral nutrition in patients with adequate gut function [7, 8]. However, 
enteral nutrition via a nasogastric tube is associated with adverse effects (e.g., nosocomial sinusitis and tracheobronchial aspiration of gastric contents) $[9,10]$, such as mask leakage with decreased NIV efficiency [11]. In a recent physiological study demonstrating improved breathing-swallowing coordination and reduced dyspnea with NIV during acute COPD exacerbations [12], an off switch added to the ventilator for use during swallowing proved effective. Such a device may allow patients to eat sufficiently, including during NIV sessions using a nasal mask, thus obviating the need for nasogastric tube feeding.

Despite the considerable emphasis placed recently on appropriate nutritional support in critically ill patients, the accurate evaluation of malnutrition and provision of adequate nutritional support remain major challenges in ICU patients $[13,14]$, especially those requiring NIV, for the above-mentioned reasons. The considerable body of evidence available on the nutritional management of patients receiving MV contrasts with the paucity of data on nutrition in patients started on NIV to treat acute respiratory failure.

To begin filling this knowledge gap, we performed a multicenter cohort study with the main objective of describing the nutritional management of patients admitted to the ICU and given first-line NIV. The secondary objectives were to assess potential associations between the type of nutritional management and patient outcomes, including the need for $\mathrm{MV}$, occurrence of infection (i.e., bacteremia, urinary tract infection, ventilatorassociated pneumonia [VAP], intensive care unit-acquired pneumonia [ICU-AP], central line-associated bloodstream infection), and death.

\section{Methods}

We used the multicenter OUTCOMEREA ${ }^{\text {tm }}$ database contributed to by physicians in 20 French ICUs with the assistance of trained database monitors, as described elsewhere [15]. This study was approved by our institutional review board (Clinical Investigation Center Ethics Committee [CECIC] Clermont-Ferrand IRB number 5891, reference number 2007-16), which waived the need for written informed consent of the participants, in accordance with French legislation on noninterventional studies. However, the patients and their next of kin were informed about the inclusion of their anonymized health data in the database, and none declined participation.

\section{Study population}

We included adults admitted to medical ICUs between 2000 and 2015 who received NIV for more than 2 consecutive days. The 2-day period was selected as a criterion for providing nutritional support [16, 17].
Exclusion criteria were previous ICU admission during the same hospital stay, postoperative period, neuromuscular disease, NIV received after extubation, and treatment limitation decisions within $24 \mathrm{~h}$ after starting NIV. We separated the patients into four groups on the basis of nutrition during the first 2 days of NIV: no nutrition $(\mathrm{NoN})$, enteral nutrition with or without parenteral nutrition (EN), parenteral nutrition only $(\mathrm{PN})$, and oral nutrition only $(\mathrm{ON})$.

\section{Outcomes}

We assessed associations between nutritional groups and the need for $\mathrm{MV}$, the occurrence of nosocomial infection (i.e., bacteremia, urinary tract infection, VAP, ICU-AP, central line-associated bloodstream infection), and death. A patient was considered as a candidate for invasive $\mathrm{MV}$ in case of loss of consciousness, hemodynamic instability, inability to maintain the airway, worsening respiratory distress, or persistently low peripheral arterial oxygen saturation $(<90 \%)$ despite $100 \%$ fraction of inspired oxygen.

Nosocomial infection was defined as bacteremia, urinary tract infection, pneumonia, or catheter-related infection occurring after $72 \mathrm{~h}$ from admission. The definition of nosocomial infection was taken from the Hospital in Europe Link for Infection Control through Surveillance (HELICS) project [18]. Bacteremia was defined as the presence of pathogenic bacteria in blood culture. Catheter-related infection was defined as a positive quantitative catheter culture $\left(\geq 10^{3}\right.$ colony-forming units $[\mathrm{CFU}] / \mathrm{ml}$ ) treated by physicians in charge. ICUAP was defined as a lower respiratory tract infection that was not incubating at the time of hospital admission, with symptom onset 2 or more days after NIV initiation. ICU-AP was suspected on the basis of new or progressive radiographic pulmonary infiltrates with at least two of the following: temperature $>38{ }^{\circ} \mathrm{C}$ or $<36{ }^{\circ} \mathrm{C}$, leukocytosis $>$ $10,000 / \mathrm{mm}^{3}$ or leukopenia $<4000 / \mathrm{mm}^{3}$, and purulent respiratory secretions [19]. The diagnosis was confirmed by a quantitative sputum culture $>10^{5} \mathrm{CFU} / \mathrm{ml}$, bronchoalveolar lavage (BAL) culture $>10^{4} \mathrm{CFU} / \mathrm{ml}$, or plugged telescoping catheter culture $>10^{3} \mathrm{CFU} / \mathrm{ml}$. VAP was defined as persistent pulmonary infiltrates seen on chest radiographs combined with purulent tracheal secretions and/or body temperature $\geq 38.5{ }^{\circ} \mathrm{C}$ or $\leq 36.5{ }^{\circ} \mathrm{C}$ and/or peripheral blood leukocyte count $\geq 10,000 / \mathrm{mm}^{3}$ or $\leq$ $4000 / \mathrm{mm}^{3}$. A definite diagnosis of VAP required microbiological confirmation by quantitative culture from a protected specimen brush $\left(>10^{3} \mathrm{CFU} / \mathrm{ml}\right)$, plugged telescopic catheter specimen $\left(>10^{3} \mathrm{CFU} / \mathrm{ml}\right)$, BAL fluid specimen $\left(>10^{4} \mathrm{CFU} / \mathrm{ml}\right)$, or endotracheal aspirate $\left(>10^{5} \mathrm{CFU} / \mathrm{ml}\right)$. A urinary tract infection was defined as a quantitative culture containing $\geq 10^{5} \mathrm{CFU} / \mathrm{ml}$ of one or two organisms. 


\section{Data collection}

The baseline characteristics listed in Table 1 were collected at ICU admission. The McCabe and Jackson classification was used to estimate the prognosis of any preexisting disease (rapidly fatal, ultimately fatal, or nonfatal).

\section{Quality of the database}

For most of the study variables, the data capture software immediately ran an automatic check for internal consistency, generating queries that were sent to the ICUs for resolution before incorporation of the new data into the database. In each participating ICU, data quality was checked by having a senior physician from another participating ICU review a $2 \%$ random sample of the study data from alternate years. A 1-day-long data capture training course held once annually was open to all OUTCOMEREA $^{\mathrm{TM}}$ investigators and study monitors.

\section{Statistical analysis}

Characteristics of patients and outcomes were described using frequency and percentage for qualitative variables and median and interquartile range for quantitative variables. A multivariable Cox model was built to evaluate potential associations between nutrition group $(\mathrm{NoN}$, EN, PN, or ON) and day 28 mortality. To assess potential associations linking nutrition group to the use of $\mathrm{MV}$ and to the occurrence of nosocomial infection (i.e., bacteremia, urinary tract infection, VAP, ICU-AP, central line-associated bloodstream infection) within 28 days, we used a multivariable Fine and Gray model to allow for discharge alive from the ICU as a competing event. The adequacy of the models was checked using the graphical and numerical methods of Lin et al. (1993). We looked for associations between nutrition group and ventilator-free days by day 28 using multivariable negative binomial regression. Finally, an association between

Table 1 Baseline characteristics of the 1075 patients

\begin{tabular}{|c|c|c|c|c|c|}
\hline \multirow[b]{2}{*}{ Baseline characteristics } & \multicolumn{4}{|l|}{ No. (\%) or median [IQR] } & \multirow[b]{2}{*}{$P$ value* } \\
\hline & No nutrition $(n=622)$ & Parenteral nutrition $(n=74)$ & Enteral nutrition $(n=28)$ & Oral nutrition $(n=351)$ & \\
\hline Age, years (1 missing) & $70.4[59.4-80.2]$ & $67.3[56.4-78.8]$ & $66.6[60.9-77.3]$ & $71.6[59.4-80.3]$ & 0.39 \\
\hline Male sex & $384(61.7)$ & $47(63.5)$ & $19(67.9)$ & $206(58.7)$ & 0.64 \\
\hline $\begin{array}{l}\text { Hospital LOS before ICU admission, } \\
\text { days }\end{array}$ & $1[1-3]$ & $1.5[1-5]$ & $2[1-6.5]$ & $1[1-2]$ & 0.08 \\
\hline Weight, kg (162 missing) & $73[61-87]$ & $71[62-88]$ & $61[55-74]$ & $73[60-85]$ & 0.06 \\
\hline BMl, kg/m² (270 missing) & 26 [22.8-30.9] & $25[22.2-30.2]$ & $23.4[19.2-26.7]$ & $25.5[21.8-30.5]$ & 0.09 \\
\hline Admission diagnosis (12 missing) & & & & & $<0.01$ \\
\hline COPD exacerbation & $98(16)$ & $8(11.1)$ & $2(7.4)$ & $93(26.6)$ & \\
\hline Acute respiratory failure & $366(59.6)$ & $46(63.9)$ & $13(48.1)$ & $183(52.3)$ & - \\
\hline $\begin{array}{l}\text { Coma as referral diagnosis related } \\
\text { to hypercapnia }\end{array}$ & $21(3.4)$ & $2(2.8)$ & $5(18.5)$ & $7(2)$ & - \\
\hline Miscellaneous & $129(21)$ & $16(22.2)$ & $7(25.9)$ & $67(19.1)$ & \\
\hline \multicolumn{6}{|l|}{ Chronic disease $\mathrm{a}^{\mathrm{a}}$} \\
\hline Heart failure & $144(23.2)$ & $15(20.3)$ & $4(14.3)$ & $87(24.8)$ & 0.55 \\
\hline Respiratory failure & $256(41.2)$ & $32(43.2)$ & $6(21.4)$ & $186(53)$ & $<0.01$ \\
\hline Hepatic failure & $25(4)$ & $3(4.1)$ & $0(0)$ & $8(2.3)$ & 0.36 \\
\hline Renal failure & $42(6.8)$ & $4(5.4)$ & $3(10.7)$ & $19(5.4)$ & 0.64 \\
\hline Immunosuppression & $112(18)$ & $13(17.6)$ & $4(14.3)$ & $39(11.1)$ & 0.04 \\
\hline \multicolumn{6}{|l|}{$\begin{array}{l}\text { McCabe and Jackson classification } \\
\text { (14 missing) }\end{array}$} \\
\hline Nonfatal & $277(45.3)$ & $35(48.6)$ & $11(40.7)$ & $159(45.4)$ & 0.38 \\
\hline Ultimately fatal disease & $287(46.9)$ & $31(43.1)$ & $13(48.1)$ & $176(50.3)$ & \\
\hline Fatal within 1 year & $48(7.8)$ & $6(8.3)$ & $3(11.1)$ & $15(4.3)$ & \\
\hline Charlson comorbidity index & $2[1-3]$ & $1[1-3]$ & $1.5[0.5-3]$ & $2[1-3]$ & 0.22 \\
\hline SAPS $\|$ & 37 [30-47] & $35.5[26-45]$ & $43.5[34.5-50.5]$ & $33[25-42]$ & $<0.01$ \\
\hline SOFA & $4[2-5]$ & $4[3-6]$ & $4.5[3.5-7]$ & $4[2-5]$ & 0.02 \\
\hline
\end{tabular}

Abbreviations: LOS length of stay, ICU intensive care unit, BMI Body Mass Index, COPD chronic obstructive pulmonary disease, SAPS /I Simplified Acute Physiology Score II, SOFA Sequential Organ Failure Assessment

${ }^{a}$ Assessed using the Knaus scale

${ }^{*}$ Comparaison between the groups 
nutrition group and the change in partial pressure of carbon dioxide $\left(\mathrm{PaCO}_{2}\right)$ from ICU admission to the end of the second day $\left(\triangle \mathrm{PaCO}_{2}\right)$ was sought using analysis of variance in the 772 patients with available $\triangle \mathrm{PaCO}_{2}$ data.

All models were adjusted on clinically relevant variables. Choices among collinear variables were based on clinical relevance, rate of missing variables, and reproducibility of definitions. The variables selected for adjustment were age, sex, Sequential Organ Failure Assessment (SOFA) score on the first day of NIV, chronic diseases, diabetes, obesity, main diagnosis at ICU admission, respiratory and neurologic SOFA subscores at ICU admission, and hospital length of stay before ICU admission shorter than 2 days. Missing values occurred for age $(n=1)$ and main diagnosis at ICU admission $(n=19)$ and were imputed using the median and mode, respectively.

$P$ values less than 0.05 were considered significant. Statistical analyses were performed using SAS version 9.4 software (SAS Institute, Cary, NC, USA).

\section{Results}

\section{Patients}

During the study period, of the 16,594 patients recorded in the database, 1075 (6.5\%) required first-line NIV for longer than 2 days. As shown in Table 1, NIV was performed for COPD exacerbation in 201 patients (19\%), acute respiratory failure in 608 patients (57\%), and hypoventilation associated with coma in 35 patients (3\%). During the first 2 days of NIV, 622 patients (57.8\%) received no nutrition, $28(2.6 \%)$ received EN, 74 (6.9\%) received PN only, and 351 (32.7\%) received ON only (Fig. 1).

Table 1 reports the main patient characteristics. Nutrition groups differed significantly regarding ICU admission category, main symptom at ICU admission, body weight, severity, and length of hospital stay before ICU admission. Acute illness severity as assessed by the Simplified Acute Physiology Score II was lower in the ON group than in the NoN group. The median ICU length of stay was 4 days (interquartile range, 2-7).

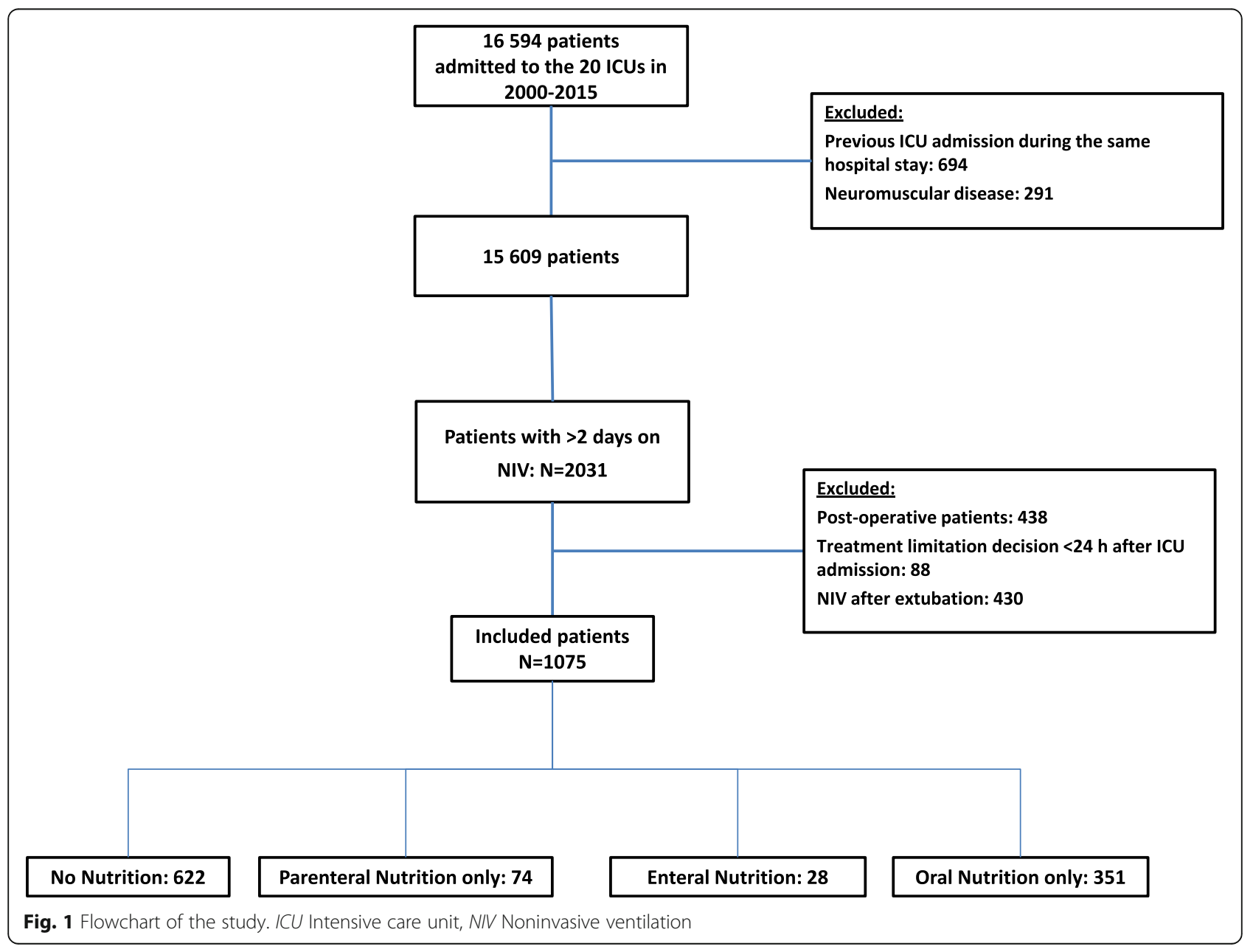




\section{Associations with type of nutrition}

Overall, within the first 28 days, 145 patients (13.5\%) developed nosocomial infection (Additional file 1: Table S1), 158 (14.7\%) required MV, and 161 (15.0\%) died. Eighty-nine patients (8.3\%) developed ICU-AP, and 42 patients (3.9\%) developed VAP. Table 2 reports the results of the multivariable analyses.

After adjustment for confounders (i.e., age, sex, hospital stay length before ICU admission $<2$ days, acute illness severity at ICU admission [SOFA score], respiratory and neurologic SOFA subscores at ICU admission, obesity, chronic disease, and main diagnosis at ICU admission), nutrition group was independently associated with higher incidence of nosocomial infection $(P=0.02)$, VAP $(P=0.002)$, and 28 -day mortality $(P=0.02)$ (Fig. 2$)$. The incidence of infection was higher in the EN group than in the NoN group (HR, 2.2; 95\% CI, 1.1-4.5; $P=$ 0.03). The occurrence of nosocomial infection was not different in the PN or ON group compared with the NoN group. The nutrition group was not associated with the occurrence of ICU-AP $(P=0.18)$. The incidence of VAP was higher in the $\mathrm{EN}$ and $\mathrm{PN}$ groups than in the NoN group (HR, 6.9; 95\% CI, 2.1-22.3; $P=0.001$; and 2.9; $95 \%$ $95 \% \mathrm{CI}, 1.1-7.4 ; P=0.03$, respectively).

Mortality was higher in the EN group than in the NoN group (HR, 2.3; 95\% CI, 1.2-4.4; $P=0.01$ ). Mortality on day 28 was not different in the PN or ON group compared with the NoN group. The number of ventilatorfree days by day 28 was significantly associated with nutrition group $(P=0.006)$. Compared with NoN, EN was associated with fewer ventilator-free days by day 28 (RR per day, 0.7; 95\% CI, 0.5-0.9). $\Delta \mathrm{PaCO}_{2}$ over the first 2 days was not associated with nutrition group.

\section{Discussion}

In this large, multicenter database study, nearly threefifths of patients fasted during the first 2 days of first-line NIV used to treat acute respiratory failure in the ICU. About one-third of patients received oral nutrition. EN and $\mathrm{PN}$ were rarely used but were more often associated with the need for invasive MV. EN, but not fasting, was associated with higher 28-day mortality. EN was also associated with a more days on ventilation. Type of nutrition was not associated with the occurrence of ICU-AP.

In a previous observational study, patients with acute respiratory failure requiring NIV often had inadequate oral food intake, particularly early during admission and as NIV duration increased [20]. Although nutritional support is now recognized as an essential component of the management of critically ill patients [17, 21, 22], the optimal intake and timing remain unclear. Positive associations between protein intake and survival have been reported in observational studies [23, 24]. A major weakness of these studies is the heterogeneity in acute illness
Table 2 Adjusted analysis of associations between type of nutrition and four 28-day outcomes: invasive mechanical ventilation, mortality, ventilator-free days, and intensive care unit-acquired pneumonia

\begin{tabular}{|c|c|c|}
\hline 28-Day outcomes & sHR $(95 \% \mathrm{Cl})$ & $P$ value \\
\hline Invasive mechanical ventilation & & $<0.0001$ \\
\hline No nutrition & 1.0 & \\
\hline Parenteral nutrition & $1.7(1.0-2.7)$ & 0.04 \\
\hline Enteral nutrition & $2.1(1.1-4.2)$ & 0.03 \\
\hline \multirow[t]{2}{*}{ Oral nutrition } & $0.5(0.3-0.7)$ & 0.0005 \\
\hline & HR $(95 \% \mathrm{Cl})$ & $P$ value \\
\hline Mortality & & 0.02 \\
\hline No nutrition & 1.0 & \\
\hline Parenteral nutrition & $1.3(0.7-2.2)$ & 0.39 \\
\hline Enteral nutrition & $2.3(1.2-4.4)$ & 0.01 \\
\hline \multirow[t]{2}{*}{ Oral nutrition } & $0.8(0.5-1.1)$ & 0.20 \\
\hline & RR $(95 \% \mathrm{Cl})$ & $P$ value \\
\hline Ventilator-free days & & 0.006 \\
\hline No nutrition & 1.0 & \\
\hline Parenteral nutrition & $0.9(0.7-1.0)$ & 0.11 \\
\hline Enteral nutrition & $0.7(0.5-0.9)$ & 0.01 \\
\hline \multirow[t]{2}{*}{ Oral nutrition } & $1.1(1.0-1.2)$ & 0.10 \\
\hline & sHR $(95 \% \mathrm{Cl})$ & $P$ value \\
\hline Nosocomial infection ${ }^{a}$ & & 0.02 \\
\hline No nutrition & 1.0 & \\
\hline Parenteral nutrition & $1.0(0.5-1.9)$ & 0.96 \\
\hline Enteral nutrition & $2.2(1.1-4.5)$ & 0.03 \\
\hline \multirow[t]{2}{*}{ Oral nutrition } & $0.7(0.5-1.0)$ & 0.06 \\
\hline & sHR $(95 \% \mathrm{Cl})$ & $P$ value \\
\hline ICU-acquired pneumonia & & 0.18 \\
\hline No nutrition & 1.0 & \\
\hline Parenteral nutrition & $1.1(0.5-2.5)$ & 0.75 \\
\hline Enteral nutrition & $2.1(0.8-5.4)$ & 0.13 \\
\hline \multirow[t]{2}{*}{ Oral nutrition } & $0.7(0.4-1.2)$ & 0.17 \\
\hline & sHR $(95 \%$ Cl) & $P$ value \\
\hline VAP & & 0.002 \\
\hline No nutrition & 1.0 & \\
\hline Parenteral nutrition & $2.9(1.1-7.4)$ & 0.03 \\
\hline Enteral nutrition & $6.9(2.1-22.3)$ & 0.001 \\
\hline Oral nutrition & $0.9(0.4-2.1)$ & 0.76 \\
\hline
\end{tabular}

Abbreviations: sHR Subdistribution hazard ratio, ICU Intensive care unit, $R R$ Relative risk, VAP Ventilator-associated pneumonia Results are given as HR for Cox models, RR for the negative binomial model, and subdistribution hazard ratio (sHR) for the Gray and Fine model. (i.e., age, sex, hospital length of stay before ICU admission < 2 days, acute illness severity at ICU admission [Sequential Organ Failure Assessment \{SOFA\} score], respiratory and neurologic SOFA subscores at ICU admission, obesity, chronic disease, and main diagnosis at ICU admission)

${ }^{a}$ Nosocomial infection includes bacteremia, urinary tract infection, VAP ICU-acquired pneumonia, central line-associated bloodstream infection 


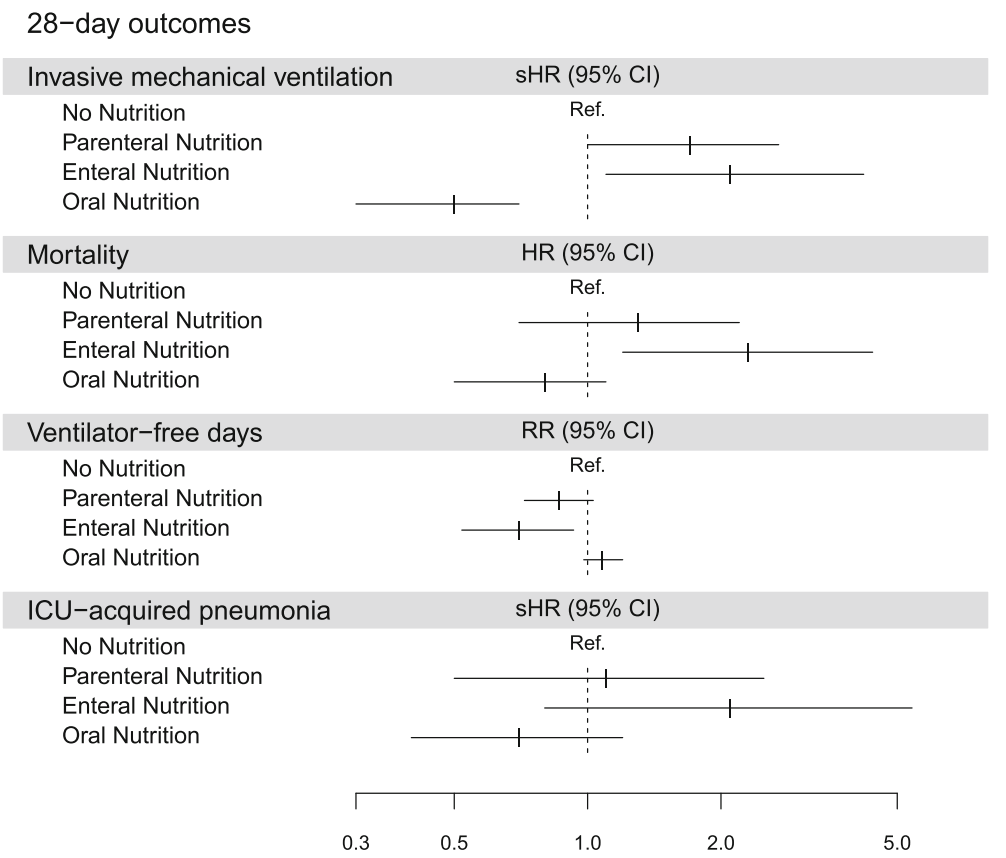

Fig. 2 Impact of nutrition group on outcome. ICU Intensive care unit, sHR Subdistribution hazard ratio, RR Relative risk

severity, which is a key potential confounder. Patients with lower severity tolerate EN better, have caloric and protein intake closer to the optimal values, and experience better outcomes. Moreover, recent methodologically sound and adequately powered randomized controlled trials have not generated unequivocal evidence that full-replacement nutrition early in the course of critical illness produces clinical benefits $[25,26]$.

In addition to timing of initiation, the delivery route is viewed as an important determinant of the effect of nutritional support. EN may produce nonnutritional benefits, including maintenance of structural and functional gut integrity and of the gut microbiome [27, 28]. However, EN may fail to provide sufficient nutrition, particularly at the acute phase of critical illness and in patients with gastrointestinal dysfunction $[29,30]$. PN may be more effective in achieving nutritional targets but is associated with infections, which are probably related to overnutrition and hyperglycemia, as shown in two meta-analyses $[31,32]$. These clinical data have translated into a consensus, expressed in both international recommendations $[17,21]$ and expert opinions $[33,34]$, that EN should be preferred in critically ill patients without contraindications to this route. CALORIE is a large, randomized trial in which researchers recently compared EN and PN started within $36 \mathrm{~h}$ after ICU admission and continued for up to 5 days in unselected ICU patients [35]. In this pragmatic trial involving 2388 patients, neither 30-day mortality nor the frequency of infections differed between the two groups. These results challenge the previously held belief that EN produces better outcomes than PN in ICU patients.

Enteral nutrition via nasogastric tube and parenteral nutrition was rarely used in our study. As previously described, enteral nutrition via a nasogastric tube is associated with adverse effects $[9,10]$, such as mask leakage with decreased NIV efficiency [11]. Furthermore, Kogo et al. observed in a retrospective study that enteral nutrition caused more airway complications in subjects receiving NIV for acute respiratory failure than in those receiving nutrition by other routes [36]. We can hypothesize that physicians promote NIV efficiency rather than nutrition during the first 2 days of NIV. These results are in accordance with those of previous studies. Indeed, Bendavid et al. showed, in a large prevalence study of nutrition practice in intensive care, that enteral feeding was prescribed to only $10 \%$ of the patients on the first day, but this number increased to more than $40 \%$ of the patients after 5 days [37].

Parenteral nutrition was used for only $7 \%$ of the patients. As suggested earlier, some physicians could be reluctant to use enteral nutrition via a nasogastric tube for patients with NIV. Moreover, a fluid-restricted strategy targeting patients with acute respiratory failure (more than half of included patients) may explain few parenteral nutrition prescriptions in the study population [38]. Here, type of nutrition was not associated with the occurrence of ICU-AP. However, occurrence of VAP was higher in the PN and EN groups. This result is coherent with the fact that the EN and PN groups were associated with a 
higher need for invasive MV. Indeed, a protective effect of NIV has been reported in single-center [39] and multicenter [40] studies and can be attributed both to the absence of an endotracheal tube bypassing the upper airways and to decreased invasiveness of the overall management. Contrary to previous results, the reported increase in infectious complications that have been associated with the parenteral route was not observed [41]. The absence of significance of this result is probably due to the lack of power, and other contributory reasons may be improvements in current management of vascular access [42].

In our study, fasting for $48 \mathrm{~h}$ after NIV initiation was not associated with 28-day mortality. In contrast, EN and PN during the first 2 days on NIV were associated with higher need for invasive MV, and EN was associated with higher 28-day mortality. The observational design of this study could not prove causality. Critically ill patients may be unable to tolerate EN, which may be associated with a higher risk of respiratory complications (e.g., mucus plug, aspiration pneumonia) [36]. EN may increase the residual gastric volume, thereby promoting bacterial colonization and the risk of aspiration pneumonia, and VAP may increase [43, 44]. Many risk factors for aspiration pneumonia have been identified, including intubation and difficult intubation, peri-intubation vomiting, anesthesia, older age, gastroparesis, reflux, impaired swallowing, mental state alteration, and cardiac arrest [45]. In our study, type of nutrition was not associated with the occurrence of ICU-AP. However, occurrence of VAP was higher in the PN and EN groups. This result is coherent with the fact that the EN and PN groups were associated with greater need for invasive MV. Moreover, nosocomial infection was higher in the EN group. We can hypothesize that the higher mortality was due to higher occurrence of nosocomial infection. We cannot exclude the negative impact of overfeeding. As previously demonstrated, high protein intake may lead to azotemia, hypertonic dehydration, and metabolic acidosis [46]. Large amounts of intravenous glucose may result in hyperglycemia, hypertriglyceridemia, and hepatic steatosis [47], which can, however, be prevented to a considerable extent by insulin therapy targeting normoglycemia [48]. Moreover, NIV decreases the work and therefore the energy needs of the diaphragm [49]. Previous data suggest that oversupply of energy relative to needs may worsen diaphragmatic dysfunction [50].

Our study has several limitations. The patients were identified retrospectively from the database, and we cannot exclude selection bias. Choice of nutrition route was made by clinicians without a specific protocol. Moreover, unfortunately, we cannot provide the amount of calories and protein for each group. NIV practices may have varied across the study centers. The indications to perform NIV were heterogeneous but in accordance with recommendations. Decisions of application (i.e., continuous session, intermittent) were made by attending clinicians, and total duration of NIV session was not assessed; thus, we cannot exclude the possibility that these modalities influenced the choice of the route of nutrition. However, our study was a multicenter study in 20 French ICUs, and our results are in accordance with previous results. Reeves et al. demonstrated that patients with acute respiratory failure requiring NIV often had inadequate oral intake, particularly with increasing time on NIV and earlier during their hospital admission [20]. Moreover, a retrospective study can detect associations but cannot provide evidence of causality. Although we adjusted for potential confounders, we cannot exclude the possibility that the observed associations were related to a clustering effect (i.e., to variables that were not adjusted for and that were related both to the choice of nutrition type and to outcomes).

\section{Conclusions}

Most patients received no nutrition at all during the first 2 days of first-line NIV. Early EN in a heterogeneous population was independently associated with higher 28-day mortality and fewer ventilator-free days. Additional studies are required to assess the need for, as well as the best timing and route of, nutritional support in this specific population.

\section{Additional file}

Additional file 1: Table S1. Description of interface used for NIV and type of exhibited complications according to nutritional groups. (DOCX $17 \mathrm{~kb}$ )

\section{Abbreviations}

BAL: Bronchoalveolar lavage; BMI: Body mass index; CFU: Colony-forming units; COPD: Chronic obstructive pulmonary disease; EN: Enteral nutrition; ICU: Intensive care unit; ICU-AP: Intensive care unit-acquired pneumonia; LOS: Length of stay; MV: Mechanical ventilation; NIV: Noninvasive ventilation; NoN: No nutrition; ON: Oral nutrition; $\mathrm{PaCO}_{2}$ : Partial pressure of carbon dioxide; PN: Parenteral nutrition; RR: Relative risk; SAPS II: Simplified Acute Physiology Score II; sHR: Subdistribution hazard ratio; SOFA: Sequential Organ Failure Assessment; VAP: Ventilator-associated pneumonia

\section{Acknowledgements}

We thank A. Wolfe, MD, for revising the manuscript.

Members of the OUTCOMEREA Study Group

Scientific Committee: Jean-François Timsit (Medical and Infectious Diseases ICU, Bichat-Claude Bernard Hospital, Paris; UMR 1137 Inserm, Paris Diderot University Infection Antimicrobials Modelling Evolution [IAME], Paris); Elie Azoulay (Medical ICU, Saint Louis Hospital, Paris); Maïté Garrouste-Orgeas (ICU, Saint-Joseph Hospital, Paris); Jean-Ralph Zahar (Infection Control Unit, Angers Hospital, Angers, France); Christophe Adrie (ICU, Delafontaine Hospital, Saint Denis, and Physiology, Cochin Hospital, Paris); Michael Darmon (Medical ICU, Saint Etienne University Hospital, Saint-Etienne, France); and Christophe Clec'h (ICU, Avicenne Hospital, Bobigny, and UMR 1137 Inserm, Paris Diderot University IAME, Paris).

Biostatistical and Information System Expertise: Jean-Francois Timsit (Medical and Infectious Diseases ICU, Bichat-Claude Bernard Hospital, Paris; UMR 1137 Inserm, Paris Diderot University IAME, Paris); Corinne Alberti (Medical Computer Sciences and Biostatistics Department, Robert Debré Hospital, Paris); Stephane Ruckly (OUTCOMEREA Organization and Inserm UMR 1137 IAME, Paris); 
Sébastien Bailly (Grenoble University Hospital, Inserm UMR 1137 IAME, Paris); Lenka Styfalova (ICUREsearch, Paris); and Aurélien Vannieuwenhuyze (Tourcoing, France).

OUTCOMEREA Database Investigators: Christophe Adrie (ICU, Delafontaine Hospital, Saint Denis, and Physiology, Cochin Hospital, Paris); Bernard Allaouchiche (ICU, Pierre Benite Hospital, Lyon, France); Laurent Argaud (Medical ICU, Hospices Civils de Lyon, Lyon, France); Claire Ara-Somohano (Medical ICU, University Hospital, Grenoble, France); Elie Azoulay (Medical ICU, Saint Louis Hospital, Paris); Francois Barbier (Medical-Surgical ICU, Orleans, France), Jean-Pierre Bedos (ICU, Versailles Hospital, Versailles, France); Julien Bohé (ICU, Hôpital Pierre Benite, Lyon France); Lila Bouadma (ICU, Bichat Hospital, Paris); Christine Cheval (ICU, Hyeres Hospital, Hyeres, France); Christophe Clec'h (ICU, Avicenne Hospital, Bobigny, France); Michael Darmon (ICU, Saint Etienne Hospital, Saint Etienne, France); Anne-Sylvie Dumenil (Antoine Béclère Hospital, Clamart, France); Claire Dupuis (Bichat Hospital and UMR 1137 Inserm, Paris Diderot University IAME, Paris); Jean-Marie Forel (Assistance Publique - Hôpitaux Marseille, Medical ICU, Hôpital Nord Marseille); Marc Gainier (la Timone Hospital, Marseille, France); Akim Haouache (Surgical ICU, Henri Mondor Hospital, Creteil, France); Samir Jamali (ICU, Dourdan Hospital, Dourdan, France); Hatem Khallel (ICU, Cayenne General Hospital, Cayenne, France); Alexandre Lautrette (ICU, Gabriel-Montpied Hospital, Clermont-Ferrand, France); Guillaume Marcotte (Surgical ICU, Hospices Civils de Lyon, Lyon, France); Eric Le Miere (ICU, Louis Mourier Hospital, Colombes, France); Maxime Lugosi (Medical ICU, University Hospital Grenoble, Grenoble, France); Bruno Mourvillier (ICU, Bichat Hospital, Paris); Benoît Misset (ICU, Saint-Joseph Hospital, Paris); Delphine Moreau (ICU, Saint-Louis Hospital, Paris); Bruno Mourvillier (ICU, Bichat Hospital, Paris); Laurent Papazian (Hopital Nord, Marseille, France); Benjamin Planquette (Pulmonology ICU, George Pompidou Hospital, Versailles, France); Bertrand Souweine (ICU, Gabriel-Montpied Hospital, Clermont-Ferrand, France); Carole Schwebel (ICU, Albert Michallon Hospital, Grenoble, France); Nicolas Terzi (ICU, Albert Michallon Hospital, Grenoble, France); Gilles Troché (ICU, Antoine Béclère Hospital, Clamart, France); Marie Thuong (ICU, Delafontaine Hospital, Saint Denis, France); Guillaume Thierry (ICU, Saint-Louis Hospital, Paris); Dany Toledano (ICU, Gonesse Hospital, Gonesse, France); and Eric Vantalon (Surgical ICU, Saint-Joseph Hospital, Paris). Study Monitors: Julien Fournier, Caroline Tournegros, Stéphanie Bagur, Mireille Adda, Vanessa Vindrieux, Loic Ferrand, Nadira Kaddour, Boris Berthe, Samir Bekkhouche, Kaouttar Mellouk, Sylvie Conrozier, Igor Theodose, Veronique Deiler, and Sophie Letrou.

\section{Funding}

None.

\section{Availability of data and materials}

The datasets used and analyzed during the present study are available from the corresponding author on reasonable request.

\section{Authors' contributions}

$N T, M D, S R, C S$, and JFT conceived of the original protocol. NT, MD, JR, MGO, $A L, E A, B M, L A, L P, M G, D G T, S J, A S D, C S$, and JFT recorded the data. SR and JFT performed statistical analysis. NT, MD, CS, and JFT analyzed the data and drafted the manuscript. JR, MGO, AL, EA, BM, LA, LP, MG, DGT, SJ, and ASD helped to conduct the study and to draft the final manuscript. NT had full access to all the study data and takes responsibility for the content of the manuscript, including the integrity of the data and accuracy of the analysis. All authors read and approved the final manuscript.

\section{Ethics approval and consent to participate}

This study was approved by the Clermont-Ferrand Hospital institutional review board (Clinical Investigation Center Ethics Committee [CECIC] Clermont-Ferrand IRB number 5891, reference 2007-16), which waived the need for written informed consent of the participants, in accordance with French legislation on noninterventional studies.

\section{Consent for publication}

Not applicable.

\section{Competing interests}

The authors declare that they have no competing interests.

\section{Publisher's Note}

Springer Nature remains neutral with regard to jurisdictional claims in published maps and institutional affiliations.

\section{Author details}

${ }^{1}$ INSERM, U1042, Université Grenoble-Alpes, HP2, F-38000 Grenoble, France.

${ }^{2}$ Service de Réanimation Médicale, Centre Hospitalier Universitaire Grenoble - Alpes, CS10217 Grenoble, cedex 09, France. ${ }^{3}$ Medical Intensive Care Unit, Saint-Etienne University Hospital, Saint-Priest en Jarez, France. ${ }^{4}$ Medical Intensive Care Unit, Nantes University Hospital Center, Nantes, France. ${ }^{5}$ Department of Biostatistics, OUTCOMEREA ${ }^{\mathrm{TM}}$, Bobigny, France. ${ }^{6}$ UMR 1137, Infection Antimicrobials Modelling Evolution (IAME) Team 5, Decision Sciences in Infectious Diseases (DeSCID), Control and Care, Sorbonne Paris Cité, Inserm/Paris Diderot University, Paris, France. ${ }^{7}$ Polyvalent Intensive Care Unit, Groupe Hospitalier Saint-Joseph, Paris, France. ${ }^{8}$ Medical Intensive Care Unit, Gabriel Montpied University Hospital, Clermont-Ferrand, France. ${ }^{9}$ Service de Réanimation Médicale, CHU Saint-Louis, Assistance Publique - Hôpitaux de Paris, Paris, France. ${ }^{10}$ Réanimation Médicale et Infectieuse, Hôpital Bichat Claude Bernard, Assistance Publique - Hôpitaux de Paris, Paris, France.

${ }^{11}$ Medical Intensive Care Unit, Lyon University Hospital, Lyon, France.

${ }^{12}$ Réanimation des Détresses Respiratoires et Infections Sévères, Hôpital Nord Aix-Marseille University, Assistance Publique - Hôpitaux de Marseille, Unité de Recherche sur les Maladies Infectieuses et Tropicales Émergentes (URMITE), UMR CNRS 7278, Marseille, France. ${ }^{13}$ Réanimation des Urgences et Medicale, CHU la Timone 2 Marseille, Aix-Marseille Université, 13385 Marseille, France. ${ }^{14}$ Medical-Surgical Intensive Care Unit, Gonesse Hospital, Gonesse, France. ${ }^{15}$ Medical-Surgical Intensive Care Medicine Unit, Dourdan Hospital, Dourdan, France. ${ }^{16}$ Medical-Surgical Intensive Care Unit, Assistance Publique - Hôpitaux de Paris, Antoine Béclère University Hospital, Clamart, France.

${ }^{17}$ Integrated Research Center, Inserm U1039, Radiopharmaceutical Bioclinical Mixed Research Unit, University Joseph Fourier, Grenoble, France.

Received: 18 July 2017 Accepted: 23 October 2017

Published online: 29 November 2017

\section{References}

1. Demoule A, Chevret S, Carlucci A, Kouatchet A, Jaber S, Meziani F, Schmidt M, Schnell D, Clergue C, Aboab J, et al. Changing use of noninvasive ventilation in critically ill patients: trends over 15 years in francophone countries. Intensive Care Med. 2016:42(1):82-92.

2. Schnell D, Timsit JF, Darmon M, Vesin A, Goldgran-Toledano D, Dumenil AS, Garrouste-Orgeas M, Adrie C, Bouadma L, Planquette B, et al. Noninvasive mechanical ventilation in acute respiratory failure: trends in use and outcomes. Intensive Care Med. 2014;40(4):582-91.

3. Vermeeren MA, Schols AM, Wouters EF. Effects of an acute exacerbation on nutritional and metabolic profile of patients with COPD. Eur Respir J. 1997;10(10):2264-9.

4. Sridhar MK, Carter R, Lean ME, Banham SW. Resting energy expenditure and nutritional state of patients with increased oxygen cost of breathing due to emphysema, scoliosis and thoracoplasty. Thorax. 1994;49(8):781-5.

5. Agusti AG, Noguera A, Sauleda J, Sala E, Pons J, Busquets X. Systemic effects of chronic obstructive pulmonary disease. Eur Respir J. 2003;21(2):347-60.

6. Whittaker JS, Ryan CF, Buckley PA, Road JD. The effects of refeeding on peripheral and respiratory muscle function in malnourished chronic obstructive pulmonary disease patients. Am Rev Respir Dis. 1990;142(2):283-8

7. Scurlock C, Mechanick J. Early nutrition support in the intensive care unit: a US perspective. Curr Opin Clin Nutr Metab Care. 2008;11(2):152-5.

8. Gramlich L, Kichian K, Pinilla J, Rodych NJ, Dhaliwal R, Heyland DK. Does enteral nutrition compared to parenteral nutrition result in better outcomes in critically ill adult patients? A systematic review of the literature. Nutrition. 2004;20(10):843-8.

9. George DL, Falk PS, Umberto Meduri G, Leeper Jr KV, Wunderink RG, Steere EL, Nunnally FK, Beckford N, Mayhall CG. Nosocomial sinusitis in patients in the medical intensive care unit: a prospective epidemiological study. Clin Infect Dis. 1998;27(3):463-70.

10. Metheny NA, Clouse RE, Chang YH, Stewart BJ, Oliver DA, Kollef MH. Tracheobronchial aspiration of gastric contents in critically ill tube-fed patients: frequency, outcomes, and risk factors. Crit Care Med. 2006;34(4):1007-15. 
11. So EC, Chen $\mathrm{YH}$, Wong KL, Poon PW, Huang BM. A new mask designed for patients implanted with a nasogastric tube. Med Eng Phys. 2008;30(8):1020-3.

12. Terzi N, Normand H, Dumanowski E, Ramakers M, Seguin A, Daubin C, Valette X, Masson R, Sauneuf B, Charbonneau P, et al. Noninvasive ventilation and breathing-swallowing interplay in chronic obstructive pulmonary disease. Crit Care Med. 2014;42(3):565-73.

13. Kattelmann KK, Hise M, Russell M, Charney P, Stokes M, Compher C. Preliminary evidence for a medical nutrition therapy protocol: enteral feedings for critically ill patients. J Am Diet Assoc. 2006;106(8):1226-41.

14. Peterson SJ, Tsai AA, Scala CM, Sowa DC, Sheean PM, Braunschweig CL. Adequacy of oral intake in critically ill patients 1 week after extubation. Am Diet Assoc. 2010;110(3):427-33.

15. Lautrette A, Garrouste-Orgeas M, Bertrand PM, Goldgran-Toledano D, Jamali S, Laurent V, Argaud L, Schwebel C, Mourvillier B, Darmon M, et al. Respective impact of no escalation of treatment, withholding and withdrawal of life-sustaining treatment on ICU patients' prognosis: a multicenter study of the Outcomerea Research Group. Intensive Care Med. 2015;41(10):1763-72

16. McClave SA, Martindale RG, Vanek WW, McCarthy M, Roberts P, Taylor B, Ochoa JB, Napolitano L, Cresci G, A.S.P.E.N. Board of Directors; American College of Critical Care Medicine; Society of Critical Care Medicine. Guidelines for the Provision and Assessment of Nutrition Support Therapy in the Adult Critically III Patient: Society of Critical Care Medicine (SCCM) and American Society for Parenteral and Enteral Nutrition (A.S.P.E.N.). JPEN J Parenter Enteral Nutr. 2009;33(3):277-316.

17. Taylor BE, McClave SA, Martindale RG, Warren MM, Johnson DR, Braunschweig C, McCarthy MS, Davanos E, Rice TW, Cresci GA, et al. Guidelines for the Provision and Assessment of Nutrition Support Therapy in the Adult Critically III Patient: Society of Critical Care Medicine (SCCM) and American Society for Parenteral and Enteral Nutrition (A.S.P.E.N.). Crit Care Med. 2016:44(2):390-438.

18. Mertens R, Van Den Berg JM, Fabry J, Jepsen OB. HELICS: a European project to standardise the surveillance of hospital acquired infection, 1994-1995. Euro Surveill. 1996:1(4):28-30.

19. Kalil AC, Metersky ML, Klompas M, Muscedere J, Sweeney DA, Palmer LB, Napolitano LM, O'Grady NP, Bartlett JG, Carratala J, et al. Management of adults with hospital-acquired and ventilator-associated pneumonia: 2016 clinical practice guidelines by the Infectious Diseases Society of America and the American Thoracic Society. Clin Infect Dis. 2016;63(5):e61-111.

20. Reeves A, White H, Sosnowski K, Tran K, Jones M, Palmer M. Energy and protein intakes of hospitalised patients with acute respiratory failure receiving non-invasive ventilation. Clin Nutr. 2014;33(6):1068-73.

21. Casaer MP, Van den Berghe $G$. Nutrition in the acute phase of critical illness. N Engl J Med. 2014;370(13):1227-36.

22. McClave SA, Taylor BE, Martindale RG, Warren MM, Johnson DR, Braunschweig C, McCarthy MS, Davanos E, Rice TW, Cresci GA, et al. Guidelines for the provision and assessment of nutrition support therapy in the adult critically ill patient: Society of Critical Care Medicine (SCCM) and American Society for Parenteral and Enteral Nutrition (A.S.P.E.N.). JPEN J Parenter Enteral Nutr. 2016;40(2):159-211.

23. Weijs PJ, Stapel SN, de Groot SD, Driessen RH, de Jong E, Girbes AR, van Schijndel RJS, Beishuizen A. Optimal protein and energy nutrition decreases mortality in mechanically ventilated, critically ill patients: a prospective observational cohort study. JPEN J Parenter Enteral Nutr. 2012;36(1):60-8.

24. Allingstrup MJ, Esmailzadeh N, Wilkens Knudsen A, Espersen K, Hartvig Jensen T, Wiis J, Perner A, Kondrup J. Provision of protein and energy in relation to measured requirements in intensive care patients. Clin Nutr. 2012;31(4):462-8.

25. Casaer MP, Mesotten D, Hermans G, Wouters PJ, Schetz M, Meyfroidt G, Van Cromphaut S, Ingels C, Meersseman P, Muller J, et al. Early versus late parenteral nutrition in critically ill adults. N Engl J Med. 2011;365(6):506-17.

26. National Heart, Lung, and Blood Institute Acute Respiratory Distress Syndrome (ARDS) Clinical Trials Network. Initial trophic vs full enteral feeding in patients with acute lung injury: the EDEN randomized trial. JAMA. 2012;307(8):795-803.

27. Barrett $M$, Demehri FR, Teitelbaum DH. Intestine, immunity, and parenteral nutrition in an era of preferred enteral feeding. Curr Opin Clin Nutr Metab Care. 2015;18(5):496-500

28. McClave SA, Martindale RG, Rice TW, Heyland DK. Feeding the critically ill patient. Crit Care Med. 2014;42(12):2600-10.

29. Cahill NE, Dhaliwal R, Day AG, Jiang X, Heyland DK. Nutrition therapy in the critical care setting: what is "best achievable" practice? An international multicenter observational study. Crit Care Med. 2010;38(2):395-401.
30. Gungabissoon U, Hacquoil K, Bains C, Irizarry M, Dukes G, Williamson R, Deane AM, Heyland DK. Prevalence, risk factors, clinical consequences, and treatment of enteral feed intolerance during critical illness. JPEN J Parenter Enteral Nutr. 2015;39(4):441-8.

31. Heyland DK, MacDonald S, Keefe L, Drover JW. Total parenteral nutrition in the critically ill patient: a meta-analysis. JAMA. 1998;280(23):2013-9.

32. Peter JV, Moran JL, Phillips-Hughes J. A metaanalysis of treatment outcomes of early enteral versus early parenteral nutrition in hospitalized patients. Crit Care Med. 2005;33(1):213-20. discussion 260-1.

33. Preiser JC, van Zanten AR, Berger MM, Biolo G, Casaer MP, Doig GS, Griffiths RD, Heyland DK, Hiesmayr M, lapichino G, et al. Metabolic and nutritional support of critically ill patients: consensus and controversies. Crit Care. 2015;19:35.

34. Singer P, Hiesmayr M, Biolo G, Felbinger TW, Berger MM, Goeters C, Kondrup J, Wunder C, Pichard C. Pragmatic approach to nutrition in the ICU: expert opinion regarding which calorie protein target. Clin Nutr. 2014;33(2):246-51.

35. Harvey SE, Parrott F, Harrison DA, Bear DE, Segaran E, Beale R, Bellingan G, Leonard R, Mythen MG, Rowan KM, et al. Trial of the route of early nutritional support in critically ill adults. N Engl J Med. 2014;371(18):1673-84.

36. Kogo M, Nagata K, Morimoto T, Ito J, Sato Y, Teraoka S, Fujimoto D, Nakagawa A, Otsuka K, Tomii K. Enteral nutrition is a risk factor for airway complications in subjects undergoing noninvasive ventilation for acute respiratory failure. Respir Care. 2017;62(4):459-67.

37. Bendavid I, Singer $P$, Theilla M, Themessl-Huber M, Sulz I, Mouhieddine M Schuh C, Mora B, Hiesmayr M. NutritionDay ICU: a 7 year worldwide prevalence study of nutrition practice in intensive care. Clin Nutr. 2017;36(4):1122-9.

38. National Heart, Lung, and Blood Institute Acute Respiratory Distress Syndrome (ARDS) Clinical Trials Network. Comparison of two fluid-management strategies in acute lung injury. N Engl J Med. 2006;354(24):2564-75.

39. Girou E, Schortgen F, Delclaux C, Brun-Buisson C, Blot F, Lefort Y, Lemaire F, Brochard L. Association of noninvasive ventilation with nosocomial infections and survival in critically ill patients. JAMA. 2000;284(18):2361-7.

40. Antonelli M, Conti G, Moro ML, Esquinas A, Gonzalez-Diaz G, Confalonieri M, Pelaia P, Principi T, Gregoretti C, Beltrame F, et al. Predictors of failure of noninvasive positive pressure ventilation in patients with acute hypoxemic respiratory failure: a multi-center study. Intensive Care Med. 2001;27(11):1718-28.

41. Simpson F, Doig GS. Parenteral vs. enteral nutrition in the critically ill patient: a meta-analysis of trials using the intention to treat principle. Intensive Care Med. 2005;31(1):12-23.

42. Bion J, Richardson A, Hibbert P, Beer J, Abrusci T, McCutcheon M, Cassidy J, Eddleston J, Gunning K, Bellingan G, et al. 'Matching Michigan': a 2-year stepped interventional programme to minimise central venous catheterblood stream infections in intensive care units in England. BMJ Qual Saf. 2013:22(2):110-23.

43. Metheny NA. Preventing respiratory complications of tube feedings: evidence-based practice. Am J Crit Care. 2006;15(4):360-9.

44. Artinian V, Krayem H, DiGiovine B. Effects of early enteral feeding on the outcome of critically ill mechanically ventilated medical patients. Chest. 2006;129(4):960-7

45. DeLegge MH. Aspiration pneumonia: incidence, mortality, and at-risk populations. JPEN J Parenter Enteral Nutr. 2002;26(6 Suppl):S19-24. discussion S24-5.

46. Ziegler TR. Parenteral nutrition in the critically ill patient. N Engl J Med. 2009;361(11):1088-97.

47. Barret JP, Jeschke MG, Herndon DN. Fatty infiltration of the liver in severely burned pediatric patients: autopsy findings and clinical implications. J Trauma. 2001;51(4):736-9.

48. Mesotten D, Wauters J, Van den Berghe G, Wouters PJ, Milants I, Wilmer A. The effect of strict blood glucose control on biliary sludge and cholestasis in critically ill patients. J Clin Endocrinol Metab. 2009:94(7):2345-52.

49. Petrof BJ, Jaber S, Matecki S. Ventilator-induced diaphragmatic dysfunction. Curr Opin Crit Care. 2010;16(1):19-25

50. Picard M, Jung B, Liang F, Azuelos I, Hussain S, Goldberg P, Godin R, Danialou G, Chaturvedi R, Rygiel K, et al. Mitochondrial dysfunction and lipid accumulation in the human diaphragm during mechanical ventilation. Am J Respir Crit Care Med. 2012;186(11):1140-9. 